\title{
Gambaran fungsi ginjal pada penderita sindrom koroner akut
}

\author{
${ }^{1}$ Albertha M. Kristin \\ ${ }^{2}$ Agnes L. Panda \\ ${ }^{2}$ Janry Pangemanan
}

\author{
${ }^{1}$ Kandidat Skripsi Fakultas Kedokteran Universitas Sam Ratulangi Manado \\ ${ }^{2}$ Bagian / SMF Kardiologi Fakultas Kedokteran Universitas Sam Ratulangi Manado \\ RSUP Prof. Dr. R. D. Kandou Manado \\ Email: alberthakristin12089@yahoo.com
}

\begin{abstract}
Acute Coronary Syndrome (ACS) refers to a condition involving chest discomfort or other symptoms due to the lack of oxygen supply to the heart muscle due to coronary artery disorders. According to the 2008 World Health Organization (WHO) report, ACS is the first cause of death in the world with $12.8 \%$ mortality. Many studies confirmed that ACS was correlated with various factors that aggravated the kidney function. The formation of atherosclerotic lesions will cause constriction of the blood vessels resulting in decreased blood flow to the kidneys which leads to a decrease in Glomerular Filtration Rate (GFR). This study aimed to obtain the description of kidney function in patients with ACS. This was a descriptive study with a cross sectional design using secondary data from medical records of patients as a reference. Samples were 73 ACS patients. Most of the patients were in the age group 51-60 years. There were more male patients than females. GFR decline in patients with Unstable Angina Pectoris (UAP) was 27.17\%; the Non ST-segment Elevation Myocardial Infraction (NSTEMI) was 40.74\%; and ST-segment Elevation Myocardial Infraction (STEMI) was 72.73\%. The co-morbidities were: Chronic Kidney Disease (CKD) $39.44 \%$, hypertension $25.35 \%$, diabetes $22.54 \%$, and $12.68 \%$ as others. Conclusion: Most of the ACS patients were male, and the largest age group was 51-60 years. The most number of comorbidities was CKD and the largest decrease in GFR was in patients with STEMI.
\end{abstract}

Keywords: renal function, glomerular filtration rate, ACS, CKD

\begin{abstract}
Abstrak: Sindrom Koroner Akut (SKA) merupakan suatu kondisi yang melibatkan rasa tidak nyaman pada dada atau gejala lainnya oleh karena kurangnya pasokan oksigen ke otot jantung akibat gangguan pada arteri koroner. Menurut laporan WHO tahun 2008, SKA merupakan penyebab kematian pertama di dunia dengan mortalitas $12,8 \%$. Telah banyak penelitian yang mengatakan bahwa SKA berkorelasi dengan berbagai faktor yang memperberat kerja ginjal. Terbentuknya lesi aterosklerosis akan menyebabkan terjadinya konstriksi pembuluh darah sehingga terjadi penurunan aliran darah ke ginjal yang menyebabkan terjadinya penurunan Laju Filtrasi Glomerulus (LFG). Penelitian ini bertujuan untuk mendapatkan gambaran fungsi ginjal pada penderita SKA. Metode penelitian ialah deskriptif dengan desain potong lintang menggunakan data sekunder dari rekam medik pasien sebagai acuan. Jumlah sampel penelitian ini sebanyak 73 pasien. Penderita terbanyak pada kelompok usia 51-60 tahun, jenis kelamin laki-laki lebih banyak daripada perempuan. Penurunan LFG pada penderita Unstable Angina Pectoris (UAP) sebanyak 27,17\%, Non ST-segment Elevation Myocardial Infraction (NSTEMI) 40,74\% dan ST-segment Elevation Myocardial Infraction (STEMI) 72,73\%. Penyakit penyerta pada kejadian SKA diantaranya Chronic Kidney Disease (CKD) sebanyak 39,44\%, hipertensi 25,35\%, diabetes $22,54 \%$ dan lain-lain $12,68 \%$. Simpulan: Kelompok usia yang menderita SKA terbanyak adalah 51-60 tahun. Penderita SKA terbanyak berjenis kelamin laki-laki dan kelompok usia terbanyak ialah 51-60 tahun. Penyakit penyerta terbanyak ialah CKD dan penurunan LFG terbanyak pada penderita dengan STEMI.
\end{abstract}

Kata kunci: fungsi ginjal, laju filtrasi glomerulus, sindrom koroner akut 
Sindrom Koroner Akut (SKA) merupakan suatu kondisi yang melibatkan rasa tidak nyaman pada dada atau gejala lainnya oleh karena kurangnya pasokan oksigen ke otot jantung akibat gangguan pada arteri koroner. ${ }^{1}$ Sindrom koroner akut meliputi Unstable Angina Pectoris (UAP), Non STsegment Elevation Myocardial Infraction (NSTEMI), dan ST-segment Elevation Myocardial Infraction (STEMI). ${ }^{2}$

Menurut laporan World Health Organization (WHO) tahun 2008, SKA merupakan penyebab kematian pertama di dunia dengan mortalitas 12,8\%. Sindrom Koroner Akut juga merupakan penyebab kematian keempat di negara berpenghasilan rendah dengan mortalitas 6,1\%, penyebab kematian pertama di negara berpenghasilan sedang dan tinggi dengan mortalitas 13,7\% dan $15,6 \%{ }^{3}$

Menurut data dari Riset Kesehatan Dasar (RISKESDAS) tahun 2013, ${ }^{4}$ prevalensi SKA yang terdiagnosis dokter tertinggi di Sulawesi Tenggara (0,8\%), kemudian Sulawesi Utara, DKI Jakarta dan aceh masing-masing 0,7\%. Sementara SKA yang terdiagnosis dan menunjukkan gejala tertinggi di Nusa Tenggara Timur (4,4\%), Sulawesi Tengah (3,8\%), Sulawesi Selatan (2,9\%), dan Sulawesi Barat (2,6\%).

Terdapat keterkaitan antara organ jantung dan ginjal dimana jantung berfungsi sebagai pompa yang mengalirkan darah ke seluruh tubuh termasuk ginjal, kemudian ginjal berfungsi untuk mengatur tekanan darah serta volume cairan. ${ }^{5}$

Pada keadaan patologis seperti adanya lesi aterosklerosis yang merupakan faktor risiko terjadinya SKA, akan merangsang pelepasan endothelial derived contracting factor (EDCF) sehingga menyebabkan terjadinya konstriksi pembuluh darah termasuk pembuluh-pembuluh darah ginjal. Konstriksi pembuluh darah ginjal akan menyebabkan terjadinya penurunan aliran darah ke ginjal sehingga menyebabkan penurunan laju filtrasi glomerulus. ${ }^{6}$ Fungsi ginjal diukur dengan melihat estimasi Laju Filtrasi Glomerulus yang dapat dihitung dengan berbagai metode. ${ }^{7-9}$

Telah banyak penelitian yang menunjukkan bahwa SKA berkorelasi dengan berbagai faktor yang memperberat kerja ginjal, tetapi saat ini belum tersedia data mengenai profil fungsi ginjal pada pasien SKA di Sulawesi Utara. Penelitian ini bertujuan untuk melihat gambaran fungsi ginjal pada pasien SKA di Sulawesi Utara, khususnya di RSUP. Prof. Dr. R. D. Kandou Manado.

\section{METODE PENELITIAN}

Penelitian ini bersifat deskriptif dengan desain potong lintang. Penelitian dilakukan di Pusat Jantung dan Pembuluh Darah RSUP. Prof. Dr. R.D Kandou Manado pada bulan Juli - September 2015. Populasi penelitian ialah semua penderita sindrom koroner akut yang dirawat inap di Pusat Jantung dan Pembuluh darah RSUP Prof. Dr. R. D. Kandou Manado periode Juli September 2015. Sampel penelitian ini ialah penderita yang memenuhi kriteria inklusi berupa pemeriksaan fungsi ginjal ureum dan kreatinin, sedangkan kriteria eksklusi ialah penderita SKA yang datanya tidak lengkap.

Variabel penelitian terdiri dari variabel bebas yaitu tipe SKA dan variabael terikat yaitu laju filtrasi glomerulus. Data yang diperoleh disajikan dalam bentuk tabel distribusi frekuensi.

\section{HASIL PENELITIAN}

Berdasarkan data penderita SKA periode Juli hingga September 2015 di Pusat Jantung dan Pembuluh Darah RSUP. Prof. Dr. R.D Kandou Manado didapatkan sebanyak 77 kasus SKA. Dari jumlah yang didapatkan, data pasien yang memenuhi kriteria inklusi di Pusat Jantung dan Pembuluh Darah RSUP. Prof. Dr. R.D Kandou Manado berjumlah 73 kasus.

\section{Distribusi berdasarkan Usia}

Dari 73 kasus SKA yang ditemukan di Pusat jantung dan Pembuluh Darah RSUP. Prof. Dr. R.D Kandou Manado periode Juli hingga September 2015, frekuensi tertinggi berdasarkan usia yaitu golongan usia 51-60 tahun sebanyak 27 kasus (36,99\%), 61-70 tahun sebanyak 20 kasus (27,40\%), 41-50 
tahun sebanyak 12 kasus (16,44\%), 71-80 tahun sebanyak 8 kasus $(10,96 \%),>80$ tahun sebanyak 4 kasus (5,48\%), kemudian $<30$ tahun dan 31-40 tahun masing-masing satu kasus dengan perentase sebesar $(1,37 \%)$.

Tabel 1. Distribusi Penderita SKA Berdasarkan Usia

\begin{tabular}{ccc} 
Usia (tahun) & $\mathrm{n}$ & $\%$ \\
\cline { 2 - 3 }$<30$ & 1 & 1,37 \\
$31-40$ & 1 & 1,37 \\
$41-50$ & 12 & 16,44 \\
$51-60$ & 27 & 36,99 \\
$61-70$ & 20 & 27,40 \\
$71-80$ & 8 & 10,96 \\
$>80$ & 4 & 5,48 \\
Total & 73 & 100 \\
\hline
\end{tabular}

\section{Distribusi berdasarkan Jenis Kelamin}

Dari 73 kasus Sindrom Koroner Akut di Pusat Jantung dan Pembuluh Darah RSUP. Prof. Dr. R.D Kandou Manado periode Juli hingga September 2015, menurut hasil pengumpulan data berdasarkan jenis kelamin yang didapatkan dari penelitian, frekuensi paling tertinggi adalah laki-laki, sebanyak 58 kasus (79,45\%), kemudian pada perempuan sebanyak 15 kasus (20,55\%).

Tabel 2. Distribusi berdasarkan Jenis Kelamin

\begin{tabular}{ccc}
\hline Jenis Kelamin & $\mathrm{n}$ & $\%$ \\
\hline Perempuan & 15 & 20,55 \\
Laki-laki & 58 & 79,45 \\
Total & 73 & 100 \\
\hline
\end{tabular}

\section{Distribusi berdasarkan Tipe SKA}

Berdasarkan hasil survei dari data rekam medik di Pusat Jantung dan Pembuluh Darah RSUP. Prof. Dr. R. D. Kandou Manado periode Juli-September 2015 diperoleh 73 kasus yang sesuai dengan kriteria inklusi. Berdasarkan Tabel 3 dapat dinilai bahwa jumlah kasus Sindrom Koroner Akut yang paling banyak adalah NSTEMI yaitu sebanyak 27 kasus (36,99\%), diikuti oleh UAP sebanyak 24 kasus (32,88\%), dan STEMI sebanyak 22 kasus $(30,14 \%)$.
Tabel 3. Distribusi Berdasarkan Tipe SKA

\begin{tabular}{ccccc}
\hline \multirow{2}{*}{ Tipe SKA } & \multicolumn{3}{c}{ Bulan } & $\%$ \\
\cline { 2 - 4 } & 7 & 8 & 9 & \\
\hline UAP & 6 & 14 & 4 & 32.88 \\
NSTEMI & 19 & 3 & 5 & 36.99 \\
STEMI & 3 & 11 & 8 & 30.14 \\
Total & 28 & 28 & 17 & 100 \\
\hline
\end{tabular}

\section{Distribusi Berdasarkan Penyakit Penyerta}

Dari 73 kasus SKA di Pusat Jantung dan Pembuluh Darah RSUP. Prof. Dr. R.D. Kandou Manado periode Juli - September 2015 dari 73 kasus, didapatkan 71 kasus SKA dengan penyakit penyerta. Penyakit penyerta yang tebanyak ialah CKD 28 kasus (39,44\%), disusul dengan Hipertensi sebanyak 18 kasus (25,35\%), Diabetes sebanyak 16 kasus (22,54\%), dan lain lain sebanyak 9 kasus (12,68\%).

Tabel 4. Distribusi Berdasarkan Penyakit Penyerta

\begin{tabular}{ccc}
\hline Penyakit & Jumlah & $\%$ \\
Penyerta & Kasus & 39.44 \\
CKD & 28 & 25.35 \\
Hipertensi & 18 & 22.54 \\
Diabetes & 16 & 12.68 \\
Lain-lain & 9 & 100 \\
Total & 71 & \\
\hline
\end{tabular}

\section{Distribusi LFG Berdasarkan Usia} Penderita SKA

Pada penelitian ini didapatkan dari 73 penderita SKA yang mengalami penurunan LFG sebanyak 34 orang (46,58\%), dan yang normal sebanyak 39 orang (53,42\%). Penderita SKA $<30$ tahun yang mengalami penurunan LFG sebanyak 1 orang (1,36\%), yang LFGnya normal tidak ada, usia 31-40 tahun terdapat 1 orang pasien dan tidak mengalami penurunan LFG, terdapat 12 orang pada kelompok usia 41-50 tahun, 3 (4,11\%) diantaranya mengalami penurunan LFG, 9 (12,33\%) diantaranya normal. Terdapat 27 orang pada kelompok usia 5160 tahun, 11 (15,07\%) diantaranya mengalami penurunan LFG dan 16 (21,92\%) normal. 
Tabel 5. Distribusi LFG berdasarkan Usia Penderita SKA

\begin{tabular}{ccc}
\hline \multirow{2}{*}{$\begin{array}{c}\text { Usia } \\
\text { Tahun })\end{array}$} & \multicolumn{2}{c}{ LFG } \\
\cline { 2 - 3 }$(\mathrm{n}=\%)$ & $\begin{array}{c}\text { Normurun } \\
(\mathrm{n}=\%)\end{array}$ \\
\hline$<30$ & $1(1,37 \%)$ & 0 \\
$31-40$ & 0 & $1(1,37 \%)$ \\
$41-50$ & $3(4,11 \%)$ & $9(12,33 \%)$ \\
$51-60$ & $11(15,07 \%)$ & $16(21,92 \%)$ \\
$61-70$ & $11(15,07 \%)$ & $9(12,33 \%)$ \\
$71-80$ & $5(6,85 \%)$ & $3(4,11 \%)$ \\
$>80$ & $3(4,11 \%)$ & $1(1,37 \%)$ \\
Total & \multicolumn{2}{c}{$73(100 \%)$} \\
\hline
\end{tabular}

Pada kelompok usia 61-70 tahun terdapat 20 orang pasien, $11(15,07 \%)$ mengalami penurunan LFG dan 9 (12,33\%) normal. Terdapat 8 orang pada kelompok usia 71-80 tahun 5 (6,85\%) diantaranya mengalami penurunan LFG dan 3 (4,11\%) diantaranya normal. Pada kelompok usia $>80$ tahun terdapat 4 orang, $3(4,11 \%)$ diantaranya mengalami penurunan LFG dan $1(1,37 \%)$ orang normal.

\section{Distribusi LFG berdasarkan Tipe SKA}

Pada penelitian ini 24 kasus didiagnosa dengan UAP, 7 kasus (29,17\%) diantaranya mengalami penurunan LFG, 17 kasus (70,83\%) normal. Terdapat 27 kasus yang didiagnosa NSTEMI, 11 kasus (40,74\%) diantaranya mengalami penurunan LFG, 16 kasus (59,26\%) normal. Terdapat 22 kasus yang didiagnosis dengan STEMI, 16 kasus (72,73\%) diantaranya mengalami penurunan LFG dan 6 kasus (27,27\%) normal.

Tabel 6. Distribusi LFG berdasarkan Tipe SKA

\begin{tabular}{cccc}
\hline \multirow{2}{*}{ Diagnosis } & \multicolumn{2}{c}{ LFG } & Total \\
\cline { 2 - 3 } & $\begin{array}{c}\text { Menurun } \\
(\mathrm{n}=\%)\end{array}$ & $\begin{array}{c}\text { Normal } \\
(\mathrm{n}=\%)\end{array}$ & \\
\hline UAP & $7(29,17 \%)$ & $17(70,83 \%)$ & 24 \\
NSTEMI & $11(40,74 \%)$ & $16(59,26 \%)$ & 27 \\
STEMI & $16(72,73 \%)$ & $6(27,27 \%)$ & 22 \\
\hline
\end{tabular}

\section{BAHASAN}

Pada penelitian ini ditemukan 73 penderita sindrom koroner akut yang di rawat inap di RSUP Prof. Dr. R.D Kandou Manado selama periode Juli - September 2015. Pada bulan Juli sebanyak 28 kasus, bulan Agustus sebanyak 28 kasus dan bulan September sebanyak 17 kasus.

Dari 73 kasus tersebut, jenis sindrom koroner akut yang terbanyak ialah NSTEMI yaitu sebanyak 27 kasus (36,99\%), kemudian disusul dengan UAP sebanyak 24 kasus (32,88\%), dan STEMI sebanyak 22 kasus (30,14\%). Hal ini sesuai dengan kepustakaan yang mengatakan bahwa prevalensi NSTEMI dan UAP lebih tinggi dibandingkandengan STEMI. ${ }^{10}$ SKA juga merupakan penyebab kematian pertama di dunia, hal ini sesuai dengan data dari WHO tahun 2008, ditemukan kasus SKA sekitar $12,8 \%$, dan terus mengalami peningkatan dari tahun ke tahun. ${ }^{3}$

Hasil dari data yang didapatkan dari golongan usia, penderita terbanyak ialah pada golongan usia 51-60 tahun sebanyak 29 kasus (39,73\%), diikuti dengan golongan usia 61-70 tahun sebanyak 19 kasus (26,03\%). Hal ini sesuai dengan penelitian yang dilakukan Khairunisa ${ }^{11}$ di Rumah Sakit Umum Pusat Haji Adam Malik Medan pada tahun 2011, diperoleh bahwa proporsi penderita SKA menurut usia yang tertinggi adalah penderita dengan kelompok usia 51-60 tahun dengan persentase 39,17\%.

Menurut jenis kelamin persentase tertinggi ialah laki-laki sebanyak 58 kasus (79,45\%) dan perempuan sebanyak 15 kasus (20,55\%). Hal ini sesuai dengan penelitian Ismantri yang menyatakan bahwa penderita SKA terbanyak adalah laki-laki dengan persentase sebesar 75,9\%. Hal ini disebabkan karena sebelum memasuki masa menopause wanita memiliki hormos estrogen yang berfungsi sebagai protektan terhadap kejadian aterosklerosis. $^{12}$

Hasil data yang didapat dari penyakit penyerta, terdapat 71 kasus sindrom koroner akut yang disertai dengan penyakit penyerta. Sedangkan dua kasus 
lain tidak disertai penyakit penyerta atau tidak terdapat data yang lengkap. Data penyakit penyerta terbanyak adalah CKD sebanyak 28 kasus (39,44\%), hipertensi sebanyak 18 kasus (25,35\%), diabetes sebanyak 16 kasus (22,54\%) dan lain-lain sebanyak 9 kasus (12,68\%). Dari 34 penderita yang mengalami penurunan LFG, 30 diantaranya mengalami penurunan LFG yang disertai dengan penyakit penyerta. Menurut penelitian yang dilakukan Fried et al. ${ }^{13}$ peningkatan kadar kreatinin yang mempengaruhi LFG tidak hanya disebabkan oleh CKD tetapi dapat juga disebabkan oleh hipertensi, kadar trigliserida yang tinggi diabetes, serta peningkatan kadar kreatinin juga dapat menjadi penanda adanya aterosklerosis. Hal-hal tersebut juga merupakan faktor pencetus meningkatnya risiko penyakit kardiovaskular.

Hasil data yang didapat dari distribusi LFG berdasarkan tipe SKA pada penelitian ini ditemui penurunan LFG yang tertinggi pada kasus STEMI sebanyak 16 kasus (72,73\%). Pada kasus NSTEMI ditemukan sebanyak 11 kasus (40,74\%) mengalami penurunan LFG dan penurunan LFG pada kasus UAP sebanyak 7 kasus (29,17\%). Hal ini berbeda dengan penelitian Suwaidi et al. ${ }^{14}$ dimana data yang didapat kasus NSTEMI yang mengalami penurunan LFG sebanyak 41\% kasus, STEMI sebanyak $42 \%$ dan UAP $18 \%$. Hal ini mungkin disebabkan perbedaan jumlah sampel dan perbedaan umur dari tiap penderita SKA serta pengaruh dari penyakit penyerta yang ada pada penderita SKA yang di rawat di Pusat Jantung dan Pembuluh Darah RSUP. Prof. Dr. R.D Kandou Manado.

\section{SIMPULAN}

Dari hasil penelitian dan bahasan tentang gambaran fungsi ginjal pada penderita sindrom koroner akut selama periode Juli-September 2015 di Pusat Jantung dan Pembuluh Darah RSUP. Prof. Dr. R.D. Kandou dapat disimpulkan bahwa:

1. Penderita terbanyak ialah golongan usia 51-60 tahun dan jenis kelamin laki-laki
2. Penyakit penyerta terbanyak ialah CKD diikuti dengan hipertensi, diabetes, dan lain-lainnya

3. Penurunan LFG terbanyak ialah pada SKA tipe STEMI diikuti dengan NSTEMI dan UAP

\section{SARAN}

1. Kasus sindrom koroner akut di semua usia dapat ditekan dengan menjalankan pola hidup yang baik (olah raga teratur, asupan makanan rendah kolesterol, istirahat cukup), dan menghindari faktor risiko lain seperti alkohol, merokok, stres.

2. Kontrol faktor-faktor risiko sangat diperlukan untuk mencegah komplikasi lanjut baik dari SKA sendiri maupun penyakit penyerta yang ada.

\section{DAFTAR PUSTAKA}

1. Shiel WC, Stoppler MC. In: Webster's New World Medical Dictionary (3rd ed). New Jersey: Wiley Publishing, 2008.

2. Ramrakha P, Hill J. Oxford handbook of cardiology: coronary artery disease ( 1st ed). Oxford: Oxford University Press, 2006.

3. World Health Organization. The top ten causes of death. 2008. Diakses dari: http://www.who.int/mediacentre/facts heets/fs310_2008.pdf

4. Riset Kesehatan Dasar (RISKESDAS) 2013. Diakses dari: http://www.depkes.go.id/resources/do wnload/general/Hasil\%20Riskesdas\% 202013.pdf

5. Sarnak MJ, Levey AS, Schoolwerth AC, Coresh J, Culleton B, Hamm LL, et al. Kidney disease as a risk factor for development of cardiovascular disease. Circulation. 2003; 108:215469.

6. Guyton AC, Hall JE. Pembentukan Urin oleh Ginjal: Filtrasi Glomerulus, Aliran Darah Ginjal, dan Pengaturannya. Buku Ajar Fisiologi Kedokteran (11th ed). Jakarta: EGC, 2008.

7. Hartopo BA, Setianto BY, Gharini PR. Predictive value of different estimated glomerular filtration rates on hospital 
adverse events following acute myocardial infraction. The Indonesian Journal of Internal Medicine. 2013;45:114-22.

8. Herzog CA, Asinger RW, Berger AK, Charytan DM, Diez J, Hart RG, Eckardt KU, et al. Cardiovascular diease in chronic kidney disease: improving global outcomes (KDIGO). Kidney international. 2011:1-15.

9. Afiatin, Roesli R. Laju filtrasi glomerulus dengan metode eGFR. Bandung: Fakultas Kedokteran Universitas Padjadjaran, 2009.

10. Perhimpunan dokter spesialis kardiovaskular Indonesia. Pedoman tatalaksana sindrom koroner akut. 2015. [cited 2015 oktober 02]. Available from: http: //jki.or.id

11. Khairunisa R. Gambaran Jenis dan Biaya obat pada Pasien Rawat Inap dengan Sindrom Koroner Akut di Rumah
Sakit Umum Haji Adam Malik Medan pada tahun 2011. Medan: Fakultas Kedokteran Universitas Sumatera Utara; 2013.

12. Ismantri F. Prevalensi penderita penyakit jantung koroner yang menjalani intervensi koroner perkutan di Rumah Sakit Binawaluya tahun 2008-2009 [Skripsi]. Banten: Universitas Islam Negeri Syarif Hidayatullah; 2009.

13. Fried FL, Shlipak MG, Casey C. Renal insuffiency as a predictor of cardiovascular outcomes and mortality in elderly individuals. J. Am. Coll. Cardiol. 2003;41:1364-72

14. Suwaidi J, Reddan DN, Williams K, Pie per KS, Harrington RA, Califf RM, et al. Prognostic implications of abnormalities in renal function in patients with acute coronary syndromes. Circulation. 2002;106: 974-80. 